\title{
The role of the pharmacist in patient-centered medical home practices: current perspectives
}

This article was published in the following Dove Press journal:

Integrated Pharmacy Research and Practice

30 June 2014

Number of times this article has been viewed

\author{
Nancy JW Lewis' \\ Leslie A Shimp ${ }^{2}$ \\ Stuart Rockafellow ${ }^{2}$ \\ Jeffrey MTingen ${ }^{2}$ \\ $\mathrm{Hae} \mathrm{Mi} \mathrm{Choe}{ }^{3}$ \\ Marie A Marcelino ${ }^{2}$ \\ 'Private consultancy practice, \\ Rochester Hills, MI, USA; ${ }^{2}$ Clinical, \\ Social and Administrative Department, \\ University of Michigan College \\ of Pharmacy, Ann Arbor, MI, USA; \\ ${ }^{3}$ Department of Pharmacy Services, \\ University of Michigan Health System, \\ Ann Arbor, MI, USA
}

Correspondence: Nancy JW Lewis 3233 Parkwood Drive, Rochester Hills, MI, 48306, USA

Email njwlewis@earthlink.net

\begin{abstract}
Patient-centered medical homes (PCMHs) are the centerpiece of primary care transformation in the US. They are intended to improve care coordination and communication, enhance health care quality and patient experiences, and lower health care costs by linking patients to a physician-led interdisciplinary health care team. PCMHs are widely supported by health care associations, payers, and employers. Health care accreditation organizations have created performance measures that promote the adoption of PCMH core attributes. Public and private payers are increasingly providing incentives and bonuses related to performance measure status. Evidence-based prescription, medication adherence, medication use coordination, and systems to support medication safety are all necessary components of PCMHs. Pharmacists have unique knowledge and skills that can complement the care provided by other PCMH team members. Their experience in drug therapy assessments, medication therapy management, and population health has documented benefits, both in terms of patient health outcomes and health care costs. Through collaborative care, pharmacists can assist physicians and other prescribers in medication management and thus improve prescriber productivity and patient access to care. Pharmacists are engaged in PCMHs through both employment and contractual arrangements. While some pharmacists serve a unique PCMH, others work within practice networks that serve practices within a geographical area. Financial support for pharmacist-provided services includes university funding, external grant funding, payer reimbursement, and allocation of PCMH incentives and bonus funds. There is growing support for pharmacist integration into PCMHs; however, more convincing cost-effectiveness data, as well as performance measures requiring the unique skills of pharmacists, may be needed before pharmacist-provided PCMH services become more widely adopted. Given the continued evolution of the PCMH model of care, ongoing opportunities exist for pharmacists to create an optimal care model that is suitable for PCMHs and rewarding for their profession.
\end{abstract}

Keywords: pharmacy practice, multidisciplinary care, advanced practice, pharmaceutical care

\section{Introduction}

Even as US per capita health care expenditures remain the highest in the world, improvements in morbidity and mortality within the USA have not kept pace with other nations. ${ }^{1}$ In an attempt to rein in costs and improve outcomes, the USA is placing new emphasis on primary health care. New care models, coupled with performance measures and payment reform, have been introduced and health information technology adoption encouraged. ${ }^{2}$ While health care cost containment is a primary catalyst for these initiatives, the focus on primary care is also driven by quality of care concerns, health care demands from an aging population, and upward chronic disease trends. 
Patient-centered medical homes (PCMHs) are the centerpiece of primary care transformation. PCMHs organize primary care to emphasize care coordination and communication to improve health care quality and lower costs. They seek to create a more satisfying health care experience by fostering partnerships between patients and their health care team. ${ }^{2,3}$ The PCMH care model has seven core attributes: 1) each patient should have a personal physician; 2) care is provided by a physician-led interdisciplinary team; 3 ) care has a whole-person orientation; 4) care is coordinated across the spectrum of health care services and settings; 5) quality and safety are consistently pursued through system-based and evidence-based approaches; 6) access to care is enhanced; and 7) payment processes recognize the added value of PCMH-provided care. ${ }^{2,4,5}$ The PCMH model relies on critical structural components, such as shared use of health information technology, process and outcome measurements to advance practice performance, established trusting relationships among providers and patients, and adequate financial reimbursement. ${ }^{2,3}$

\section{Manuscript objectives}

Medication management is central to the core attributes of the PCMH model. This review will: 1) explore the pharmacist's role within the PCMH model of care; and 2) describe potential delivery and payment structures for these services. Different perspectives surrounding pharmacists' roles and medication management within PCMHs are presented to characterize the support and challenges to pharmacists' integration into PCMHs.

The core attributes of the PCMH model are well defined; however, the structure and processes by which to incorporate these into delivery systems is still quite fluid. While initial research indicates the value of PCMHs in improving quality of care, lowering health care costs, and improving patient experiences, ${ }^{6-8}$ the PCMH care model is largely unproven, with much of the supporting data coming from the evaluation of model components rather than the entire care model. ${ }^{2}$ The optimal team structures, processes of care, appropriate measurement matrixes, and the effects of performance measures and payment strategies on access and quality of care are still unknown. ${ }^{9}$ It is within this evolving care model that pharmacists must determine how they can best contribute to improved patient health outcomes.

\section{History of the PCMH model}

The American Academy of Pediatrics initially advocated medical homes, in 1967, as a means to coordinate care for children with special needs. ${ }^{5}$ Over the years, other physician associations and the World Health Organization embraced the medical home concept. ${ }^{2}$ In 2001, the Institute of Medicine set forth a comprehensive framework for patient-centered care in its report "Crossing the Quality Chasm". ${ }^{10}$ This report supported team-based primary care and urged health care practices to reengineer services to address patient needs and preferences for care delivery. It also advocated for evidencebased clinical decisions, integrated use of information technology, interdisciplinary professional education, and payment methods that supported PCMH core attributes.

The American Recovery and Reinvestment Act of 2009 dramatically advanced the creation of a health technology infrastructure to support PCMHs, ${ }^{11}$ via incentive payments to physician practices for the establishment of electronic health records (EHRs). Key EHR adoption goals include improved coordination of care among health professionals and across settings of care, avoidance of duplicative care, and the ability to measure and evaluate care across populations.

The Patient Protection and Affordable Care Act of 2010 further stimulated PCMH adoption by funding demonstration projects, such as the Comprehensive Primary Care Initiative, in which Medicare and private payers collaborated to support coordination of care through primary care providers. ${ }^{12}$ State Medicaid programs and private foundations funded similar efforts. ${ }^{13}$ Together, these projects developed policies and the infrastructure that support the PCMH concept.

However, the PCMH model would not be created or sustained unless payment reforms rewarded its adoption. As a foundation for payment reform, a national coalition of physician associations, employers, health plans, consumer groups, labor unions, and health care quality improvement organizations developed eligibility criteria for PCMH recognition. ${ }^{3}$ These criteria encourage medical practices to adopt the core attributes of the PCMH model. Health care accreditation associations, such as the National Committee for Quality Assurance, the Accreditation Association for Ambulatory Health Care (formerly known as the Utilization Review Accreditation Commission), and the Joint Commission adopted these criteria. Recognition gained through these programs paved the way for medical practices to receive bonuses and higher payment rates from private and public payers.

\section{Medication-related problems within PCMHs}

Adequate medication management is based on three principles: 1) evidence-based prescribing is a necessary 
component of quality care; 2) medication adherence is essential for medication safety; and 3 ) coordination of medication use across settings of care is required for continuity of care. In the absence of adequate management, the burden of medication-related problems for health care costs and poor health outcomes is well recognized. Approximately $\$ 200$ billion worth of expenditures were attributed to drug-related problems in $2000 .{ }^{14}$ For every $\$ 1.00$ spent on drug cost nationally, $\$ 1.30$ is spent managing drug adverse events. ${ }^{14}$ Medication nonadherence is associated with an estimated $\$ 100$ billion in direct and indirect costs. ${ }^{15}$ Improper use of medications contributes to nearly 100,000 premature deaths each year. ${ }^{16}$ Of Medicare beneficiaries who take five or more medications for chronic conditions, one-third suffer an adverse event each year. ${ }^{17}$ The desire for improved medication management within PCMHs is illustrated by the development of performance measures that seek to increase evidence-based prescription and medication adherence. ${ }^{18-20}$

\section{Pharmacist contributions to PCMHs}

PCMHs are built upon interdisciplinary care teams composed of providers with complementary skills who work together to achieve shared goals related to patient care and outcomes. ${ }^{21}$ Given their drug therapy and medication management expertise, pharmacists are uniquely situated to complement the diagnostic expertise of prescribers. ${ }^{22-24}$ Pharmacists participate in patient medication management and/or in organizational policies and procedures, at a programmatic or system-wide level.

\section{Quality and safety of care}

Strong empiric evidence supporting pharmacist inclusion within PCMH teams comes from the extensive literature that documents positive patient health outcomes associated with pharmacists' care ${ }^{25-28}$ (Table 1). Pharmacist drug therapy assessments can improve prescription appropriateness, increase medication adherence, and lower medication and/or health care costs. ${ }^{29,30}$ Medication therapy management (MTM) initiatives can also improve health outcomes (Table 2). The Asheville Project, one of the longest studied endeavors in pharmacist care, demonstrated the positive impact of community pharmacists' care for patients with diabetes, asthma, hypertension, and/or dyslipidemia. ${ }^{31-34}$ One of the largest studies of collaborative pharmacist-physician care found a $20 \%$ relative increase ( $15 \%$ absolute increase) in the number of patients meeting therapeutic goals. ${ }^{35}$

Numerous studies have also shown patient care and economic benefits when pharmacists were incorporated into team-based care. ${ }^{36-41}$ Medication out-of-pocket costs and employer costs for medications were lower for 128 patients undergoing a drug therapy assessment compared with a comparison group matched on sex and age.$^{30}$ In the Asheville study, the employer return on investment was 4:1 for diabetes patients. ${ }^{32}$ For patients with asthma, pharmacists achieved a sixfold reduction in emergency department (ED) visits for asthma exacerbations. ${ }^{33}$ Significant cost savings per patient

Table I Pharmacist contributions to PCMHs

\begin{tabular}{|c|c|c|c|}
\hline Core attribute & $\begin{array}{l}\text { Selected pharmacist services related } \\
\text { to core attribute }\end{array}$ & Evidence of service value & Value to PCMHs \\
\hline $\begin{array}{l}\text { Improve quality } \\
\text { and safety of care }\end{array}$ & $\begin{array}{l}\text { - Drug therapy assessment } \\
\text { - Medication therapy management } \\
\text { - Patient education } \\
\text { - Population management } \\
\text { - Drug safety alert monitoring } \\
\text { - Formulary and drug-utilization review monitoring } \\
\text { - Drug information services }\end{array}$ & $\begin{array}{l}\text { Solid data that services can improve } \\
\text { patient outcomes }{ }^{25-41}\end{array}$ & $\begin{array}{l}\text { Improvements in HEDIS } \\
\text { scores and PCMH } \\
\text { performance measures can } \\
\text { lead to financial benefits }\end{array}$ \\
\hline $\begin{array}{l}\text { Coordination } \\
\text { of care }\end{array}$ & $\begin{array}{l}\text { - Consultant for EHR development } \\
\text { - Medication list maintenance } \\
\text { - Medication reconciliation postdischarge }\end{array}$ & $\begin{array}{l}\text { Limited data are available to support } \\
\text { these services }{ }^{47-52}\end{array}$ & $\begin{array}{l}\text { Potential to improve } \\
\text { meaningful use of EHRs, } \\
\text { decrease adverse drug events, } \\
\text { lower medication costs, and } \\
\text { prevent hospital readmissions }\end{array}$ \\
\hline $\begin{array}{l}\text { Increased access } \\
\text { to care }\end{array}$ & $\begin{array}{l}\text { - CPA } \\
\text { - Telephonic services } \\
\text { - Telemonitoring services }\end{array}$ & $\begin{array}{l}\text { CPA cost effectiveness supported } \\
\text { through demonstration projects }{ }^{15,22,54-56} \\
\text { Limited data on telephonic and } \\
\text { telemonitoring service benefits }{ }^{57-60}\end{array}$ & $\begin{array}{l}\text { Under capitated payment } \\
\text { systems, expanding the } \\
\text { population served will } \\
\text { increase revenues }\end{array}$ \\
\hline
\end{tabular}

Abbreviations: CPA, collaborative practice arrangement; EHR, electronic health record; HEDIS, Healthcare Effectiveness Data and Information Set; PCMH, patientcentered medical home. 
Table 2 Medication therapy management components in the patient-centered medical home

- Creation of a comprehensive and accurate list of all currently prescribed medications, nonprescription medications, and dietary supplements

- Assessment of medications for appropriateness, efficacy, and safety

- Assessment of barriers to adherence, such as complex regimen and cost of therapy

- Creation of an individualized set of recommendations aimed at optimizing medication use and achieving therapeutic goals

- Communication of recommendations to the patient

- Provision of culturally appropriate patient education

- Documentation of the recommendation plan and communication to appropriate care providers

were realized, even after accounting for the cost of the pharmacist. Patients with hypertension and hyperlipidemia achieved sustained, significant clinical improvements that were associated with decreased cardiovascular events and related medical costs. ${ }^{34}$ The implementation of an outpatient program to manage deep vein thrombosis reported indirect cost savings through avoidance of 150 hospital admissions per year. ${ }^{35}$

Pharmacists offer a range of services and can improve medication management throughout given populations by contributing to provider medication policies and procedures (Table 3). Pharmacists also assist with health promotion programs, by increasing immunization rates or using EHRs and patient registries to identify those at risk for adverse drug reactions. . $^{42,43}$

Though fewer formal evaluations have been done of population-based services, ${ }^{44}$ given the broad impact of such services, they may be particularly cost effective for PCMHs.

Table 3 Population health pharmacist services

- Design and/or provision of interventions to assist PCMHs in meeting performance measures

- Use of patient registry and performance data to identify patients not meeting treatment goals or not receiving evidence-based care

- Development of protocols and/or the adoption of national clinical practice guidelines to assist the PCMH in providing evidence-based care

- Development of policies and procedures for managing drug recalls and shortages

- Development of policies and procedures to address FDA medication alerts

- Reviews of high-risk medication risks

- Design and/or provision of educational interventions

- Design and/or provision of medication adherence interventions

- Design and/or provision of educational programs for PCMH staff to improve medication record keeping, medication education and monitoring efforts

Abbreviations: FDA, Food and Drug Administration; PCMH, patient-centered medical home.
Devine et $\mathrm{al}^{45}$ evaluated the efforts of two pharmacists employed in a community-based, multispecialty physician group practice. The pharmacists collaborated with physicians and clinic administrators to implement programs, and pharmacy and therapeutic committee policies that focused on evidence-based medicine, therapeutic interchange, and academic detailing. Direct cost savings from a generic drug switch initiative for antihypertensive medications resulted in a $71 \%$ generic drug use rate compared with the network average rate of $43 \%$.

\section{Coordination of care}

Coordination of care is advocated within PCMHs to avoid duplication of services, thus lowering health care costs and improving safety. Coordination is largely dependent upon health information technology to share patient data across health care settings. Given their longstanding use of technology, pharmacists are uniquely qualified to assist with the design and functionality of e-prescription and medication records, clinical decision support software, and electronic alerts and reminders.

Appropriate coordination of care includes ensuring that medication prescription and use is appropriate as patients receive care from primary and specialty practitioners, and across settings of care. Medication records can be fragmented among multiple pharmacies and prescribers, and may not contain patient-selected nonprescription medicines and dietary supplements. One study reported that $78 \%$ of patients reported at least one discrepancy in their EHR medication records postvisit. ${ }^{46}$

Pharmacists can work with PCMH teams to improve the accuracy and completeness of medication records. Adverse drug events affect $11 \%$ to $17 \%$ of patients during the first weeks after hospital discharge. ${ }^{47}$ Elderly patients, patients with impaired cognitive function, those with low health literacy, or those prescribed multiple medications appear to be at particular risk for adverse events. ${ }^{47}$ It is estimated that about $20 \%$ of all adverse drug events are due to poor communication at care transitions. ${ }^{48}$

While pharmacists are well suited to reconciling medications, ${ }^{5,43,44,49}$ limited evidence exists that supports pharmacist inclusion in medication reconciliation services. In a family medicine clinic study of patients taking ten or more medications, Milone et a ${ }^{50}$ reported an average of 6.6 total discrepancies per patient, with about half noted to be clinically important. A 2009-2010 study of patients at high-risk for hospital readmission found that patients called by pharmacists had a statistically insignificant decline in readmission rates compared with those patients not called, resulting 
in an estimated $\$ 1.5$ million in annual savings. ${ }^{51}$ However, a program that included predischarge pharmacist-patient consultations and telephone follow-up after discharge found no change in the number of clinically important medication errors or adverse drug events. ${ }^{47}$ In contrast, a review of eight congestive heart failure posthospital programs showed pharmacist interventions were associated with increased medication adherence and knowledge, fewer hospital readmissions, and lower death rates; however, study design limitations in some studies were noted. ${ }^{52}$

\section{Enhancing access to care}

The new focus on primary care, coupled with the passage of the Patient Protection and Affordable Care Act to decrease financial barriers to care, will place additional demands on primary care providers at a time when the number of primary care physicians practicing and entering primary care is insufficient to meet the demand. ${ }^{53}$ Thus, integration of the PCMH team approach is one avenue to preserve patient access to care and increase physician productivity. Increased access to care and patient care productivity can be accomplished through the delegation of drug therapy optimization responsibilities from prescribers to pharmacists, via collaborative practice agreements. ${ }^{13,22,54-56}$ A collaborative agreement related to a refill authorization program showed that it saved physicians an average of 17 hours per month. ${ }^{22}$

Pharmacist inclusion in PCMHs can enhance the convenience of care. Community pharmacist affiliations with PCMHs allow patients to receive services in convenient locations with extended hours of service. ${ }^{13}$ Telephonic pharmacist-patient interactions can also offer a convenient alternative to office visits. Weidman-Evans et $\mathrm{al}^{57}$ demonstrated positive impacts on glycemic control via a pharmacist-run telephonic service in a family medicine clinic that included education and insulin titrations. In the first year, the mean decrease in hemoglobin A1c (HbA1c) was 1.55\%, with the greatest reduction in $\mathrm{HbAlc}$ occurring within the first 3 months of enrollment.

The use of telemonitoring with pharmacist involvement has been shown to improve health outcomes for patients with diabetes, heart failure, hypertension, and asthma, ${ }^{58,59}$ as has the use of teleconferencing for adolescents using metereddose inhalers. ${ }^{60}$

\section{Structural arrangements for the provision of pharmacist services}

It is generally accepted that pharmacists provide valuable services that can assist PCMHs in managing complex medication regimens. ${ }^{61}$ Integration of such services, however, depends upon designing services so they are financially attractive for both primary care practice investment and for pharmacists.

A variety of structural arrangements for pharmacist engagement in PCMHs exist. Smith et $\mathrm{al}^{26}$ outlined the major integration models as: the PCMH employs a pharmacist as a clinical staff member; the PCMH shares financial responsibility for a university-supported pharmacist who provides clinical and teaching services; or the PCMH enters a contractual arrangement for shared pharmacist services. In the latter model, the pharmacist may be employed by a provider group, health system, payer, or pharmacy, and provide patient-specific and/or population health interventions to multiple practices. PCMH networks may receive services from a network of pharmacists, a specialty pharmacy, or other entities..$^{23,26,29,39}$ The creation of group practice networks is an avenue for pharmacists aiming to meet the needs of populations that span a wide geographical area. ${ }^{62}$ Irrespective of the $\mathrm{PCMH}$-pharmacist arrangement, patients may have an additional relationship with the pharmacist from whom they receive their prescriptions. Thus, multiple pharmacists may provide medication-related services to a patient, creating the need for coordination even within medication management efforts. ${ }^{21,62}$ Key to any arrangement is the need for coordination and communication among pharmacists, other health professionals, PCMH staff, and patients to preserve continuity of care.

\section{Financial support for pharmacist services}

PCMH-pharmacist arrangements often hinge upon the availability of resources to engage pharmacist services. Arrangements built upon university-subsidized faculty and/or pharmacy resident positions blend student teaching, community service, and scholarship responsibilities. Community-based demonstration projects, as well as safety net providers, have used external funding to defray start-up and staffing costs. ${ }^{35,36,63}$

Pharmacies may offer services at varying revenue margins so that positive revenues are gained from a total package of services. Specialty pharmacies can link clinical services and product reimbursement to create partnerships with PCMHs. ${ }^{64}$ One community pharmacy-PCMH collaboration in Washington state offers a wide range of services ranging from prescriptions and medical equipment to refill authorization programs and disease-specific collaborative practice agreements. ${ }^{22}$ Other pharmacies incorporate software 
technology or pharmacy technicians into service packages to create an overall package of care that has a favorable cost profile for purchasers. Pharmacy benefit managers, health plans, and insurers have also decreased costs on a per patient basis by offering targeted telephonic pharmacist services to large networks of medical practices. ${ }^{65}$

The use of multiple funding streams can create financial stability. One pharmacist group practice model that includes nine university-affiliated medical offices found financial support through blended resources gained from quality of care incentive payments, university financial support for teaching services, and private insurer compensation for selected pharmacist services. ${ }^{66}$ While many of these models are viewed as financially sustainable, the struggle and creative solutions assembled to achieve a system of financial support is evident.

\section{Perspectives on the role of pharmacists in PCMHs}

National pharmacist organizations consistently advocate for the inclusion of pharmacists as core team members within PCMHs. The American Pharmacists Association, the American Society of Health-System Pharmacists, the American Association of Colleges of Pharmacy, and the Pennsylvania Pharmacists Association have issued formal statements or position papers that support the role of pharmacists in PCMHs. ${ }^{13,43,62,67,68}$

Pharmacists believe their integration into the PCMH team would assist medical practices in gaining $\mathrm{PCMH}$ recognition and in reaching performance targets or sharedsavings goals offered by health plans or employer groups, by reducing unnecessary ED visits, specialty consults, and hospitalizations. ${ }^{26}$ Pharmacists also note that revenues from billed pharmacist services can add to PCMH revenues. Patient receipt of both face-to-face and telephonic pharmacist-provided medication management services has also led to positive patient satisfaction ratings. ${ }^{30,69}$

While advocating for inclusion, pharmacists also debate their desired role in PCMHs. Pharmacists place a high value on being involved in direct patient care and having established relationships with other health providers. ${ }^{70}$ However, pharmacists struggle to structure service offerings so that they are professionally rewarding from a financial standpoint as well. Definition and creation of the ideal service or mix of services has proved elusive.

Pharmacists' enthusiasm for integration into PCMHs is mirrored by a growing number of government-affiliated groups that have voiced support for pharmacist patient care services. The Agency for Healthcare Research and Quality mentions pharmacists as PCMH team members, ${ }^{71}$ the Centers for disease Control and Prevention (CDC) have outlined a role for pharmacists in PCMHs, ${ }^{72}$ and the US Public Health Services have documented the benefits of pharmacist services. ${ }^{27}$ The Centers for Medicare and Medicaid Services emphasis on MTM within the Medicare Part D program has created an avenue for pharmacists to gain recognition in medication management and to create new relationships with patients and physician practices. These organizations have a broad influence on health care policies and practices, and serve as guideposts for health care payment reforms. Their support of pharmacist services lays the foundation for creating opportunities for pharmacists to fully participate in PCMHs.

Since PCMH teams are physician-led, the medical profession's perspective on pharmacists' role is important. Physician support is a known enabler for establishment of pharmacist clinical service in ambulatory care settings. ${ }^{73}$ While medical association statements on PCMHs do not name pharmacists as essential interdisciplinary team members, the role of pharmacists in patient care is recognized by the profession. ${ }^{61,74}$ Furthermore, governmental agencies and health care coalition statements that include physician input have specifically mentioned pharmacists as valued team members. ${ }^{71,72,75}$ Several studies evaluated physician views of pharmacists' services and showed that they valued pharmacist participation in patient care..$^{70,76}$ In addition, research has found that physicians accept $60 \%$ to $83 \%$ of recommendations communicated to them by pharmacists. ${ }^{29,30}$ While not directly endorsing pharmacists' services, the American Medical Association did support the addition of billing codes related to MTM, which helped support integration of pharmacists into patient care.

However, physician concerns about the affordability of incorporating pharmacists into their teams and potential care fragmentation because of the involvement of an additional team member do exist. ${ }^{61,74}$ In recent years, the American Medical Association raised concerns about the expansion of pharmacists' scope of practice. ${ }^{77,78}$ These concerns are significant since barriers at the national health policy level can hinder payment reforms that are critical for service sustainability. If and how this dichotomy of views is resolved will be key to defining the pharmacist's role in PCMHs.

PCMHs have generally been indifferent to the inclusion of pharmacists within their interdisciplinary teams. Built from existing office staff, teams typically include a core group of physicians, nurses, medical assistants, and administrative 
staff. ${ }^{2}$ New team additions have been driven by accreditation guidelines that require personnel with specialized functions related to care coordination and population management.

PCMHs are attentive to accreditation and performance measures; however, at this time, the fulfillment of these requirements does not necessitate investment in pharmacist services. The National Committee for Quality Assurance measures related to PCMH medication management call for the recording of medication use, assessment of medication effects, and the use of e-prescription software to check for drug interactions. ${ }^{79}$ Thus a practice may use e-prescription drug interaction software, and clinical decision support alerts, and employ a specially trained medical assistant or a patient navigator to ensure that the PCMH meets such criteria. The need and cost justification for the specific and nuanced drug therapy assessments and MTM services provided by pharmacists may not be readily apparent to PCMHs. Therefore, pharmacists are challenged to create a recognized and defined patient care or practice consultation role that demonstrates a unique contribution to $\mathrm{PCMH}$ excellence, in performance measures.

PCMH team structures are undoubtedly influenced by financial incentives. While payment reforms are neutral to the composition of the interdisciplinary team, the growing use of capitated payments incentivizes office practices to elevate the practice scope of lower-cost employees, such as medical assistants and patient navigators. For example, patient navigators may become responsible for maintaining medication records, while physicians shift chronic disease management to midlevel practitioners in order to care for more complex cases. Pharmacists tend to be more expensive and have a more limited scope of practice than nurse practitioners or physician assistants and thus need to have focused responsibilities in order to be cost-effective PCMH team members. ${ }^{74,75}$

Efforts to convince PCMHs to purchase pharmacists' services have had little uptake, perhaps due to limited resources as practices have invested in health information technology and other clinical transformation resources. In addition, while the majority of numerous demonstration projects and research studies show the benefit of MTM interventions, ${ }^{28}$ true experimental design studies are rare. A review of nearly 1,800 MTM publications found that only eight met selection criteria as randomized, controlled trials. ${ }^{80} \mathrm{~A}$ Cochrane review of the impact of pharmacist services indicated that the variances in study design complicated the ability to draw conclusions. ${ }^{81}$ In contrast, others have questioned the impact of pharmacist MTM interventions since most data have been derived from demonstration projects rather than ongoing "real-world" programs. ${ }^{82}$

\section{Need for future research}

Critical questions related to the most cost-effective structure for the provision of pharmacist services within PCMHs need to be answered before pharmacists will be widely incorporated into this new model of care. Specifically, research into the cost effectiveness of pharmacist services compared with those of other lower-cost providers needs to be done. The relative benefits and costs of accessing pharmacists through services embedded in PCMHs versus services contracted within the medical home neighborhood must also be better understood. The patient characteristics that require the intense medication monitoring provided by clinical pharmacists need to be identified so that pharmacists' services can be directed toward their most cost-effective position within the PCMH. Lastly, the types of research methodologies that are most informative for appropriate decision making need to be identified.

\section{Conclusion}

Pharmacists possess great potential for assisting medical practices to meet the core attributes of the PCMH model of care. The cost savings, quality of care, and access requirements placed upon PCMHs are likely to drive medical practices and health plans to consider new ways to deliver care. The relentless drive to improve quality of care is likely to demand more complex interventions that require greater expertise. These factors will result in the critical consideration of pharmacist contributions. To seize this opportunity, pharmacists must be prepared to offer medical homes a compelling patient care and economic rationale for purchasing their services.

\section{Disclosure}

The authors report no conflicts of interest in this work.

\section{References}

1. Philipson T, Eber M, Lakdawalla DN, Corral M, Conti R, Goldman DP An analysis of whether higher health care spending in the United States versus Europe is 'worth it' in the case of cancer. Health Aff (Millwood). 2012;31(4):667-675.

2. Arend J, Tsang-Quinn J, Levine C, Thomas D. The patient-centered medical home: history, components, and review of the evidence. Mt Sinai J Med. 2012;79(4):433-450.

3. Ewing M. The patient-centered medical home solution to the cost-quality conundrum. J Healthc Manag. 2013;58(4):258-266.

4. American Academy of Family Physicians; American Academy of Pediatrics; American College of Physicians; American Osteopathic Association. Joint Principles of the Patient-Centered Medical Home. Washington, DC: Patient-Centered Primary Care Collaborative (PCPCC); 2007. 
5. Abrons JP, Smith M. Patient-centered medical homes: primer for pharmacists. J Am Pharm Assoc (20103). 2011;51:e38-e48.

6. Liss DT, Fishman PA, Rutter CM, et al. Outcomes among chronically ill adults in a medical home prototype. Am JManag Care. 2013;19(10): e348-e358.

7. DeVries A, Li CH, Sridhar G, Hummel JR, Breidbart S, Barron JJ. Impact of medical homes on quality, healthcare utilization, and costs. Am J Manag Care. 2012;18(9):534-544.

8. Maeng DD, Davis DE, Tomcavage J, GrafTR, Procopio KM. Improving patient experience by transforming primary care: evidence from Geisinger's patient-centered medical homes. Popul Health Manag. 2013;16(3):157-163.

9. Alexander JA, Paustian M, Wise CG, et al. Assessment and measurement of patient-centered medical home implementation: the BCBSM experience. Ann Fam Med. 2013;11 Suppl 1:S74-S81.

10. Committee on Quality of Health Care in America. Formulating new rules to redesign and improve care. In: Committee on Quality of Health Care in America [Institute of Medicine]. Crossing the Quality Chasm. A New Health System for the 21st Century. Washington, DC: National Academy Press; 2001:61-88.

11. Buntin MB, Jain SH, Blumenthal D. Health information technology: laying the infrastructure for national health reform. Health Aff (Millwood). 2010;29(6):1214-1219.

12. cms.gov [homepage on the Internet]. Comprehensive primary care initiative. Centers for Medicare and Medicaid Services; 2014 [cited January 2, 2014]. Available from: http://innovation.cms.gov/initiatives/ Comprehensive-Primary-Care-Initiative/index.html. Accessed April 12, 2014.

13. medicalhomeinfo.org [homepage on the Internet]. National demonstration projects and state initiatives. National Center for Medical Home Implementation; 2014 [cited January 2, 2014]. Available from: http://www.medicalhomeinfo.org/national/projects_and_initiatives. aspx. Accessed April 12, 2014.

14. Ernst FR, Grizzle AJ. Drug-related morbidity and mortality: updating the cost-of-illness model. J Am Pharm Assoc (Wash). 2001;41(2): 192-199.

15. Berdine H, Dougherty T, Ference J, et al. The pharmacists' role in the Patient-Centered Medical Home (PCMH): a white paper created by the Health Policy Committee of the Pennsylvania Pharmacists Association (PPA). Ann Pharmacother. 2012;46(5):723-750.

16. Johnson JA, Bootman JL. Drug-related morbidity and mortality. A cost-of-illness model. Arch Intern Med. 1995;155(18):1949-1956.

17. Hanlon JT, Schmader KE, Koronkowski MJ, et al. Adverse drug events in high risk older outpatients. J Am Geriatr Soc. 1997;45(8):945-948.

18. National Committee on Quality Assurance. Continuous Improvement and the Expansion of Quality Measurement. Washington, DC. National Committee on Quality Assurance; 2011. Available from: http://www. ncqa.org/Portals/0/SOHC-web1.pdf. Accessed December 12, 2013.

19. National Committee on Quality Assurance. Summary Table of Measures, Product Lines and Changes. Washington: National Committee on Quality Assurance; 2014. Available from: http:/www.ncqa.org/ Portals/0/HEDISQM/HEDIS2014/List_of_HEDIS_2014_Measures. pdf. Accessed May 9, 2014.

20. ncqa.org [homepage on the Internet]. HEDIS and performance measurement. National Committee on Quality Assurance; 2014 [cited December 16, 2013]. Available from: http://www.ncqa.org/tabid/59/ Default.aspx. Accessed April 12, 2014.

21. Mitchell P, Wynia M, Golden R, et al. Core Principles and Values of Effective Team-Based Health Care [discussion paper]. Washington, DC: Institute of Medicine; 2012.

22. Erickson S, Hambleton J. A pharmacy's journey toward the patientcentered medical home. J Am Pharm Assoc (2003). 2011;51(2): 156-160.

23. Smith M, Bates DW, Bodenheimer T, Cleary PD. Why pharmacists belong in the medical home. Health Aff (Millwood). 2010;29(5): 906-913.
24. Adams K, Corrigan JM, editors. Priority Areas for National Action. Transforming Health Care Quality. Washington, DC: The National Academy Press; 2003.

25. Strand LM, Cipolle RJ, Morley PC, Frakes MJ. The impact of pharmaceutical care practice on the practitioner and the patient in the ambulatory practice setting: twenty-five years of experience. Curr Pharm Des. 2004;10(31):3987-4001.

26. Smith M, Bates DW, Bodenheimer TS. Pharmacists belong in accountable care organizations and integrated care teams. Health Aff (Millwood). 2013;32(11):1963-1970.

27. Gilbertson S, Yoder S, Lee MP. Improving Patient and Health System Outcomes Through Advanced Pharmacy Practice. A Report to the US Surgeon General 2011. Washington, DC: United States Public Health Service; 2011

28. Chisholm-Burns MA, Kim Lee J, Spivey CA, et al. US pharmacists' effect as team members on patient care: systematic review and metaanalyses. Med Care. 2010;48(10):923-933.

29. Shimp LA, Kucukarslan SN, Elder J, et al. Employer-based patientcentered medication therapy management program: evidence and recommendations for future programs. J Am Pharm Assoc (2003). 2012;52(6):768-776.

30. Lewis NJ, Bugdalski-Stutrud C, Abate MA, Blommel M, Wu CH, Gaither CA. The Medication Assessment Program: comprehensive medication assessments for persons taking multiple medications for chronic diseases. J Am Pharm Assoc (2003). 2008;48(2): 171-180.

31. Cranor CW, Christensen DB. The Asheville Project: short-term outcomes of a community pharmacy diabetes care program. JAm Pharm Assoc (Wash). 2003;43(2):149-159.

32. Cranor CW, Bunting BA, Christensen DB. The Asheville Project: longterm clinical and economic outcomes of a community pharmacy diabetes care program. J Am Pharm Assoc (Wash). 2003;43(2):173-184.

33. Bunting BA, Cranor CW. The Asheville Project: long-term clinical, humanistic, and economic outcomes of a community-based medication therapy management program for asthma. J Am Pharm Assoc (2003). 2006;46(2):133-147.

34. Bunting BA, Smith BH, Sutherland SE: The Asheville Project: clinical and economic outcomes of a community-based long-term medication therapy management program for hypertension and dyslipidemia. $J A m$ Pharm Assoc (2003). 2008;48(1):23-31.

35. Isetts BJ, Brummel AR, de Oliveira DR, Moen DW. Managing drugrelated morbidity and mortality in the patient-centered medical home. Med Care. 2012;50(11):997-1001.

36. Fera T, Bluml BM, Ellis WM, Schaller CW, Garrett DG. The Diabetes Ten City Challenge: Interim clinical and humanistic outcomes of a multisite community pharmacy diabetes care program. J Am Pharm Assoc (2003). 2008;48(2):181-190.

37. Fera T, Bluml BM, Ellis WM. Diabetes Ten City Challenge: final economic and clinical results. J Am Pharm Assoc (2003). 2009;49(3): 383-391.

38. Wubben DP, Vivian EM. Effects of pharmacist outpatient interventions on adults with diabetes mellitus: a systematic review. Pharmacotherapy. 2008;28(4):421-436.

39. Isetts BJ, Schondelmeyer SW, Artz MB, et al. Clinical and economic outcomes of medication therapy management services: the Minnesota experience. J Am Pharm Assoc (2003). 2008;48(2):203-214.

40. Berdine HJ, Skomo ML. Development and integration of pharmacist clinical services into the patient-centered medical home. J Am Pharm Assoc (2003). 2012;52(5):661-667.

41. Isetts BJ, Brown LM, Schondelmeyer SW, Lenarz LA. Quality assessment of a collaborative approach for decreasing drug-related morbidity and achieving therapeutic goals. Arch Intern Med. 2003;163(15):1813-1820.

42. Jackson AN, Kogut S. Use of electronic personal health records to identify patients at risk for aspirin-induced gastrointestinal bleeding. Consult Pharm. 2013;28(5):313-318. 
43. Otsuka SH, Tayal NH, Porter K, Embi PJ, Beatty SJ. Improving herpes zoster vaccination rates through use of a clinical pharmacist and a personal health record. Am J Med. 2013;126(9):832. e1-832. e6.

44. Nigro SC, Garwood CL, Berlie H, et al. Clinical pharmacists as key members of the patient-centered medical home: an opinion statement of the Ambulatory Care Practice and Research Network of the American College of Clinical Pharmacy. Pharmacotherapy. 2014;34(1): 96-108.

45. Devine EB, Hoang S, Fisk AW, Wilson-Norton JL, Lawless NM, Louie C. Strategies to optimize medication use in the physician group practice: the role of the clinical pharmacist. J Am Pharm Assoc (2003). 2009;49(2):181-191

46. Webb JR, Feinglass J, Makoul G, et al. Can electronic health records help improve patients' understanding of medications? Am J Manag Care. 2010;16(12):919-922.

47. Kripalani S, Roumie CL, Dalal AK, et al; PILL-CVD (Pharmacist Intervention for Low Literacy in Cardiovascular Disease) Study Group Effect of a pharmacist intervention on clinically important medication errors after hospital discharge: a randomized trial. Ann Intern Med. 2012;157(1):1-10.

48. Rozich JD, Howard RJ, Justeson JM, Macken PD, Lindsay ME, Resar RK. Standardization as a mechanism to improve safety in health care. Jt Comm J Qual Saf. 2004;30(1):5-14.

49. American College of Clinical Pharmacy; Hume AL, Kirwin J, Bieber HL, et al. Improving care transitions: current practice and future opportunities for pharmacy. Pharmacotherapy. 2012;32(11):e326-e337.

50. Milone AS, Philbrick AM, Harris IM, Fallert CJ. Medication reconciliation by clinical pharmacists in an outpatient family medicine clinic. J Am Pharm Assoc (2003). 2014;54(2):281-187.

51. Kilcup M, Schultz D, Carlson J, Wilson B. Postdischarge pharmacist medication reconciliation: impact on readmission rates and financial savings. J Am Pharm Assoc (2003). 2013;53(1):78-84.

52. Ponniah A, Anderson B, Shakib S, Doecke CJ, Angley M. Pharmacists' role in the post-discharge management of patients with heart failure: a literature review. J Clin Pharm Ther. 2007;32(4):343-352.

53. Shipman SA, Sinsky CA. Expanding primary care capacity by reducing waste and improving the efficiency of care. Health Aff (Millwood). 2013;32(11):1990-1997.

54. Law AV, Gupta EK, Hata M, et al. Collaborative pharmacy practice: an update. Integrated Pharmacy Research and Practice. 2013;2:1-16.

55. National Center for Chronic Disease Prevention and Health Promotion. Collaborative Practice Agreements and Pharmacists' Patient Care Services. A Resource for Doctors, Nurses, Physician Assistants, and Other Providers. Atlanta, GA: National Center for Chronic Disease Prevention and Health Promotion; 2013. Available from: http://www. cdc.gov/dhdsp/pubs/docs/Translational_Tools_Providers.pdf. Accessed December 2, 2013.

56. National Council for Patient Information and Education. Accelerating Progress in Prescription Medicine Adherence: The Adherence Action Agenda. A National Action Plan to Address America's "Other Drug Problem”. Rockville, MD: National Council for Patient Information and Education; 2013. Available form: http:/www.bemedicinesmart.org/ A3_Report.pdf. Accessed April 12, 2014.

57. Weidman-Evans E, Evans J, Eastwood R, Fort A. Implementation of a pharmacist-run telephonic insulin titration service. J Am Pharm Assoc (2003). 2012;52(6):e266-e272.

58. Paré G, Moqadem K, Pineau G, St-Hilaire C. Clinical effects of home telemonitoring in the context of diabetes, asthma, heart failure and hypertension: a systematic review. J Med Internet Res. 2010;12(2):e21.

59. Margolis KL, Asche SE, Bergdall AR, et al. Effect of home blood pressure telemonitoring and pharmacist management on blood pressure control: a cluster randomized clinical trial. JAMA. 2013;310(1):46-56.

60. Bynum A, Hopkins D, Thomas A, Copeland N, Irwin C. The effect of telepharmacy counseling on metered-dose inhaler technique among adolescents with asthma in rural Arkansas. Telemed J E Health. 2001;7(3): 207-217.
61. aafp.org [homepage on the Internet]. Pharmacists (position paper). American Academy of Family Practitioners; 2014 [cited January 2, 2014]. Available from: http://www.aafp.org/about/policies/ all/pharmacists.html. Accessed April 12, 2014.

62. Hogue MD, Bugdalski-Stutrud C, Smith M, et al. Pharmacist engagement in medical home practices: report of the APhA-APPM Medical Home Workgroup. J Am Pharm Assoc (2003). 2013;53(2): e118-e124.

63. Moczygemba LR, Goode JV, Gatewood SB, et al. Integration of collaborative medication therapy management in a safety net patientcentered medical home. J Am Pharm Assoc (2003). 2011;51(2): $167-172$.

64. Monroe CD, Chin KY. Specialty pharmaceuticals care management in an integrated health care delivery system with electronic health records. J Manag Care Pharm. 2013;19(4):334-344.

65. Pindolia VK, Stebelsky L, Romain TM, Luoma L, Nowak SN, Gillanders F. Mitigation of medication mishaps via medication therapy management. Ann Pharmacother. 2009;43(4):611-620.

66. Choe HM, Farris KB, Stevenson JG, et al. Patient-centered medical home: developing, expanding, and sustaining a role for pharmacists. Am J Health Syst Pharm. 2012;69(12):1063-1071.

67. Daigle LA, Banek K. Pharmacists'MTM Services Key to Health Care Homes'Success. Policy Analysis. Bethesda, MD: American Society of Health-System Pharmacists; 2009.

68. Adams AJ, Clark DR, DeLander GE, et al. Report of the AACP task force on patient-centered medical homes and accountable care organizations. Am J Pharm Educ. 2013;77(7):142.

69. Moczygemba LR, Barner JC, Brown CM, et al. Patient satisfaction with a pharmacist-provided telephone medication therapy management program. Res Social Adm Pharm. 2010;6(2):143-154.

70. Farrell, B, Ward N, Dore N, et al. Working in interprofessional primary health care teams: what do pharmacists do? Res Social Adm Pharm. 2013;9(3):288-301.

71. pcmh.ahrq,gov [homepage on the Internet]. Defining the PCMH. Agency for Healthcare Research and Quality; 2014 [cited December 2, 2013]. Available from: http://www.pcmh.ahrq.gov/page/defining-pcmh. Accessed April 12, 2014.

72. National Center for Chronic Disease Prevention and Health Promotion Collaborative Practice Agreements and Pharmacists' Patient Care Services. A Resource for Pharmacists. Atlanta: GA, National Center for Chronic Disease Prevention and Health Promotion; 2013. Available from: http://www.cdc.gov/dhdsp/pubs/docs/Translational_Tools_ Pharmacists.pdf. Accessed on December 4, 1013.

73. Knapp KK, Blalock SJ, Black BL. ASHP survey of ambulatory care responsibilities of pharmacists in managed care and integrated health systems - 2001. Am J Health Syst Pharm. 2001;58(22): 2151-2166.

74. Bates DW. Role of pharmacists in the medical home. Am J Health-Syst Pharm. 2009;66(12):1116-1118.

75. Patient-Centered Primary Care Collaborative (PCPCC). The PatientCentered Medical Home: Integrating Comprehensive Medication Management to Optimize Patient Outcomes. Resource Guide. Washington, DC: Patient-Centered Primary Care Collaborative; 2012. Available from: http://www.pcpcc.org/sites/default/files/media/ medmanagement.pdf. Accessed December 4, 2013.

76. Kozminski M, Busby R, McGivney MS, Klatt PM, Hackett SR, Merenstein JH. Pharmacist integration into the medical home: qualitative analysis. J Am Pharm Assoc (2003). 2003;51(2): 173-183.

77. Agres T. AMA seeks limits to pharmacists' scope of practice. Pharmacy Practice News. 2010;37:5

78. pharmacytimes.com [homepage on the Internet]. AMA opposes giving pharmacists prescription authority. Pharmacy Times; 2012 [updated July 10, 2012; cited February 5, 2014]. Available from: http://www.pharmacytimes.com/news/AMA-Opposes-Giving-Pharmacists-PrescriptionAuthority. Accessed April 12, 2104. 
79. National Committee for Quality Assurance (NCQA). NCQA PCMH 2011 Standards, Elements and Factors. Documentation Guideline/Data Sources. Washington, DC: National Committee for Quality Assurance; 2012. Available from: http://www.ncqa.org/portals/0/Programs/Recognition/ PCMH_2011_Data_Sources_6.6.12.pdf. Accessed February 16, 2014.

80. Kucukarslan SN, Hagan AM, Shimp LA, Gaither CA, Lewis NJ. Integrating medication therapy management in the primary care medical home: A review of randomized controlled trials. Am J Health Syst Pharm. 2011;68(4):335-345.
81. Nkansah N, Mostovetsky O, Yu C, et al. Effect of outpatient pharmacists' non-dispensing roles on patient outcomes and prescribing patterns [review]. Cochrane Database Syst Rev. 2010;7:CD000336.

82. Mossialos E, Naci H, Courtin E. Expanding the role of community pharmacists: policymaking in the absence of policy-relevant evidence? Health Policy. 2013;111(2):135-148.

\section{Publish your work in this journal}

Integrated Pharmacy Research and Practice is an international, peer-reviewed, open access, online journal, publishing original research, reports, reviews and commentaries on all areas of academic and professional pharmacy practice. This journal aims to represent the academic output of pharmacists and pharmacy practice with particular focus on integrated care. All papers are carefully peer reviewed

Submit your manuscript here: http://www.dovepress.com/integrated-pharmacy-research-and-practice-journal to ensure the highest standards as well as ensuring that we are informing and stimulating pharmaceutical professionals. The manuscript management system is completely online and includes a very quick and fair peer-review system, which is all easy to use. Visit http://www.dovepress.com/testimonials.php to read real quotes from published authors. 